\title{
Author Correction: Invivo tropism of Salmonella Typhi toxin to cells expressing a multiantennal glycan receptor
}

Yi-An Yang, Sohyoung Lee, Jun Zhao, Andrew J. Thompson D, Ryan McBride, Buyankhishig Tsogtbaatar, James C. Paulson (D), Ruth Nussinov, Lingquan Deng and Jeongmin Song (D)

Correction to: Nature Microbiology https://doi.org/10.1038/s41564-017-0076-4, published online 4 December 2018.

In the version of this Letter originally published, the $x$ axis labels associated with the left and middle bars in Fig. $4 \mathrm{~d}$ were inadvertently switched; the labels should have read "Unimmunized $(n=4)$ " and "Immunized with typhoid toxoid $(n=9)$ ", respectively. This has now been amended. 